3. Arriagada R, Bergman B, Dunant A, Le Chevalier T, Pignon JP, Vansteenkiste J. International Adjuvant Lung Cancer Trial Collaborative Group. Cisplatin-based adjuvant chemotherapy in patients with completely resected non-small-cell lung cancer. $N$ Engl J Med. 2004;350:351-60.

4. Kawaguchi K, Miyaoka E, Asamura H, Nomori H, Okumura M, Fujii Y, et al. Modern surgical results of lung cancer involving neighboring structures: a retrospective analysis of 531 pT3 cases in a Japanese Lung Cancer Registry Study. J Thorac Cardiovasc Surg. 2012;144:431-7.

5. Speicher PJ, Englum BR, Ganapathi AM, Onaitis MW, D'Amico TA Berry MF. Outcomes after treatment of 17,378 patients with locally advanced (T3N0-2) non-small-cell lung cancer. Eur J Cardiothorac Surg. 2015;47: 636-41.
See Article page 256.

\section{Commentary: Is surgery better than chemoradiation for T3N1M0 non-small cell lung cancer?}

\author{
Chi-Fu Jeffrey Yang, MD
}

Currently, there are few guidelines on how to treat clinical T3N1M0 stage IIIA non-small-cell lung cancer (NSCLC). The recommendations on locally advanced lung cancer from the American College of Chest Physicians ${ }^{1}$ and the European Society for Medical Oncology ${ }^{2}$ do not specifically detail algorithms for T3N1M0 NSCLC. The National Comprehensive Cancer Network (NCCN) does provide treatment recommendations for T3N1M0 NSCLC, ${ }^{3}$ but perhaps because T3N1M0 NSCLC is relatively uncommon (especially compared with T3N0 NSCLC or T3N2 NSCLC), ${ }^{4}$ data supporting the NCCN treatment guidelines for T3N1M0 NSCLC are limited. Until now, there have been no randomized trials or prospective or retrospective studies specifically comparing definitive chemoradiation and surgery for T3N1M0 NSCLC.

In this issue of the Journal, Rahouma and colleagues ${ }^{5}$ provide much-needed data on outcomes of surgery versus definitive chemoradiation for patients with T3N1M0 NSCLC. The authors evaluated 1937 patients who underwent surgery (with induction and/or adjuvant chemotherapy with or without radiation) and 1844 patients who underwent definitive chemoradiation for clinical T3N1M0 NSCLC

\footnotetext{
From the Department of Cardiothoracic Surgery, Stanford University Medical Center, Stanford, Calif.

Disclosure: Author has nothing to disclose with regard to commercial support

Received for publication March 16, 2020; revisions received March 16, 2020; accepted for publication March 16, 2020; available ahead of print April 6, 2020.

Address for reprints: Chi-Fu Jeffrey Yang, MD, Department of Cardiothoracic Surgery, Stanford University Medical Center, 300 Pasteur Drive, Falk Building 2nd

Floor, Stanford, CA 94305-5407 (E-mail: cjyang@post.harvard.edu).

J Thorac Cardiovasc Surg 2021;161:265-6

$0022-5223 / \$ 36.00$

Copyright (c) 2020 by The American Association for Thoracic Surgery

https://doi.org/10.1016/j.jtcvs.2020.03.106
}

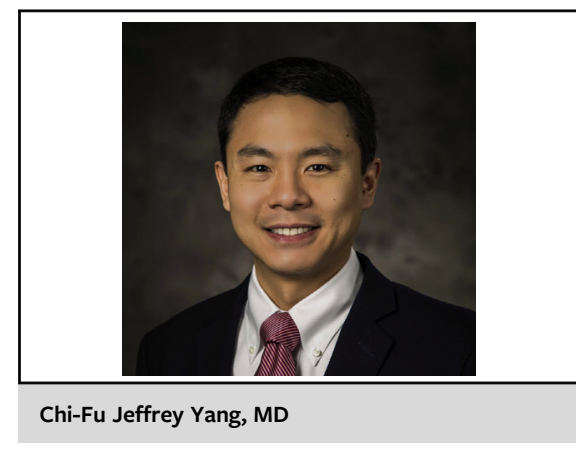

CENTRAL MESSAGE

In appropriately selected patients, surgery for T3N1Mo lung cancer is likely associated with improved survival compared with definitive chemoradiation, but further research evaluating different types of T3 tumors is needed.

between 2004 and 2014. They found that in the surgery group, among patients who did not receive preoperative chemotherapy or radiation $(\mathrm{n}=1518), 19 \%$ had pathological N0 disease and 9.5\% had pN2 disease. The surgery group had better survival than the definitive chemoradiation group in unadjusted and multivariable analyses. The authors also performed a propensity score-matched analysis in which they created a cohort of 1081 patients with cT3N1M0 NSCLC who underwent surgery (with induction and/or adjuvant chemotherapy with or without radiation) with similar baseline characteristics as 1081 patients who underwent definitive chemoradiation. Five-year overall survival was significantly greater for the surgery group when compared with the definitive chemoradiation group $(35.7 \%$ vs $19.0 \%)$.

The study has several strengths. By using the National Cancer Data Base, the authors were able to include a large 
number of patients with cT3N1M0 NSCLC and specifically evaluate the outcomes of this particular subset of stage IIIA disease. The follow-up time of around 52 months was relatively long. The authors also used included propensity score matching and multivariable Cox proportional hazards modeling to minimize confounding and bias. The authors properly acknowledged the limitations of their studythat are related to the limitations of the NCDB-which notably include lack of detail regarding the designation of T3 and details regarding the N1 (eg, hilar, interlobar and intersegmental lymph nodes) lymph nodes. It is also important to note that the definition of T3 itself has changed over time. The authors included T3 tumors that had been staged according to the 6th and 7th editions, and there have been some subtle but important changes in the 8th edition (eg, T3 tumors no longer include those greater than $7 \mathrm{~cm}$ in size but rather those between 5 and $7 \mathrm{~cm})^{6}$

There are key takeaways from the study that can be used to guide practice. First, for T3 N1 tumors, clinical staging can have significant inaccuracies. In their cohort, Rahouma and colleagues found that $19 \%$ of patients were overstaged clinically and actually had $\mathrm{pNO}$ disease. This highlights the importance of comprehensive pathological staging. Second, nationally in the United States, nearly one-half of the patients received chemoradiation as opposed to surgery, suggesting underutilization of surgery. Third, given how much better survival was in the surgery group compared with the definitive chemoradiation group, there probably is a survival benefit associated with surgery, although this finding requires further investigation in a randomized setting or at least in prospective or retrospective studies that not only evaluate T3N1M0 disease, but also specifically examine outcomes for the different types of $\mathrm{T} 3$ tumors that exist. Owing to the length of time it takes to design a randomized trial and the need for data now to guide clinical practice, further investigation of the other type of T3N1 tumors will probably rely on prospective or retrospective multi-institutional data that capture specifics about the T3 tumor and the N1 lymph node.

In the meantime, as we await findings from future analyses, this study by Rahouma and colleagues is a welcome addition to the literature and provides evidence to recommend surgery for operable T3N1 NSCLC for carefully selected patients whose care and treatment plans are discussed in a multidisciplinary setting.

\section{References}

1. Detterbeck FC, Lewis SZ, Diekemper R, Addrizzo-Harris D, Alberts WM. Executive summary: Diagnosis and management of lung cancer, 3rd ed: American College of Chest Physicians evidence-based clinical practice guidelines. Chest. 2013 143(5 Suppl):7S-37S.

2. Eberhardt WE, De Ruysscher D, Weder W, Le Péchoux C, De Leyn P, Hoffmann $\mathrm{H}$, et al. 2nd ESMO Consensus Conference in Lung Cancer: locally advanced stage III non-small-cell lung cancer. Ann Oncol. 2015;26: 1573-88.

3. National Comprehensive Cancer Network. NCCN clinical practice guidelines in oncology: non-small cell lung cancer (Version 3.2020). Available at: https:// www.nccn.org/professionals/physician_gls/default.aspx. Accessed March 25, 2020 .

4. Goldstraw P, Chansky K, Crowley J, Rami-Porta R, Asamura H, Eberhardt WE, et al. The IASLC Lung Cancer Staging Project: Proposals for revision of the TNM stage groupings in the forthcoming (eighth) edition of the TNM Classification for lung Cancer. J Thorac Oncol. 2016;11:39-51.

5. Rahouma M, Kamel M, Nasar A, Harrison S, Lee B, Port J, et al. Treatment of cT3N1M0/IIIA non-small cell lung cancer and the risk of underuse of surgery. $J$ Thorac Cardiovasc Surg. 2021;161:256-63.e1.

6. Amin MB, Edge SB, Greene F, Byrd DR, Brookland RK, Washington MK, et al., eds. AJCC Cancer Staging Manual. 8th ed. Chicago: Springer International; 2017. 